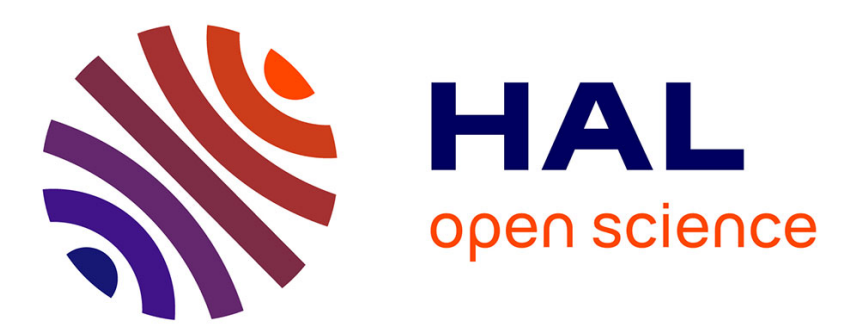

\title{
Characterization of elastic shells by the use of the wavelet transform
}

\author{
Ginette Saracco, Philippe Guillemain, Richard Kronland-Martinet
}

\section{To cite this version:}

Ginette Saracco, Philippe Guillemain, Richard Kronland-Martinet. Characterization of elastic shells by the use of the wavelet transform. Ultrasonics Symposium, Dec 1990, Honolulu, United States. pp.881-885. hal-00177246

\section{HAL Id: hal-00177246 \\ https://hal.science/hal-00177246}

Submitted on 9 Jan 2008

HAL is a multi-disciplinary open access archive for the deposit and dissemination of scientific research documents, whether they are published or not. The documents may come from teaching and research institutions in France or abroad, or from public or private research centers.
L'archive ouverte pluridisciplinaire HAL, est destinée au dépôt et à la diffusion de documents scientifiques de niveau recherche, publiés ou non, émanant des établissements d'enseignement et de recherche français ou étrangers, des laboratoires publics ou privés. 
IEEE Ultrasonics Symposium,

Honolulu, Hawai, Dec 4-7, 1990

IEEE-Ultrasonics, vol2, 881-885, 1990

\title{
CHARACTERIZATION OF ELASTIC SHELLS BY THIE USE OF THE WAVELET TRANSFORM.
}

\author{
Saracco $G^{*}$, Guillemain $P^{* *}$, Kronland-Marinet $R^{* * *}$ \\ * C.N.R.S.-L.M.A., Equipe ultrasons, 31 Ch. J. Aiguier, 13402 Marseille cedex O9 FRANCE \\ ** C.N.R.S.-L.M.A., Equipe I.M, 31 Ch. J. Aiguier, 13402 Marseille cedex 09 FRANCE \\ *** Pemanerit address CN.R.S.L.M.A., Equipe I.M, 31 Ch. $\}$. Aiguier, 13402 Marseille cedex 09 FRANCE \\ Present address: Stanford University, C.C.R.MA Dep of Music, Stanford, C.A. 94305-8180 USA
}

\begin{abstract}
This paper concerns the characterization of elastic targets inmersed in a fluid and submitted to an acoustic impulse. Time-frequency methods have already been used in the case of scatterers of simple geometric shape. We have chosen the wavelet transform for its particular properties, such as linearity and local analysis at $\Delta \mathrm{f} / \mathrm{f}=\mathrm{c}^{\text {ste }}$. We have developped an algorithm based on the behavior of the phase of the transform, which enables us to extract modulation laws (related to the dispersion law of the phase velocity), even for close echoes. In the case of spherical elastic shells, we have applied this method on both experimental and computer-generated signals and have pointed out the good relation between theoretical and experimental results.
\end{abstract}

\section{1- Introduction}

We are interested in the characterization of targets of simple geometric shape from the analysis of their acoustic response. This problem requires on the one hand the knowledge of the mechanisms of the surface waves generation and on the other hand, the choice of relevant parameters for the identification [1-11].

In this paper, we will limit ourselves to the study of signals back-scattered by spherical elastic shells in water submitted to an acoustic impulse. The parameters usually estimated are: kind of waves, arrival time of waves packets, group velocity, resonance froquencies and maxima of energy.

From a general point of vicw, the back-scattered pressure ficld can be decomposed into a geometric pressure (geometric wave) and surface pressure (surface wave and its successive echos around the target).

If the surface or packets waves are the same for targets of the same shape, the dispersion law of their phase velocity changes with respect to their thickness and their chemical composition. Targets characterization (ie: detection and identification of surface waves), requires time-frequency methods. We will focus on the estimation of frequency modulation laws of the waves packets by the use of the wavelet transform. The use of this method is justified by its linearity and localization properties.

\section{2- Description of the physical problem.}

This problem has been mainly approached ty the works of Uberall, Flax, Derem $[1,12,13]$.

In particular, Uberall has proved the relation between the winding of the surface waves around the scatterer and the resonance phenomenon [12]. For instance, we have a resonance for $\pi+1 / 2$ wave length for a spherical shell, and n wave length for a cylinder one.

The surface waves can be separated in two classes: the waves having a support in the fluid media (Stoneley, Franz waves called creeping waves), and the ones where the support is on the elastic scatterer (Rayleigh and whispering waves). Franz and whispering waves are related to the goometry of the arget.

For an incident plate wave, the pressure scattered by a spherical elastic shell is given by:

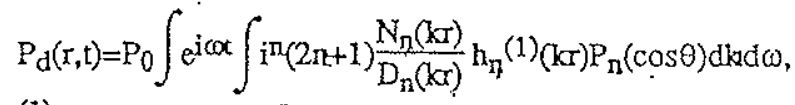
(1)

Po represents the amplitude of the incident wave;

$N_{n}$ and $D_{n}$ are functions depending of the target geomecry. They are written as $(6 \times 6)$ determinant taking into account the boundary conditions $[3,8]$. The resonances coming from the interfaces (shell) corresponds to the singularities of these functions $[3,12]$;

$b_{n}(1)$ represents the spherical Hankel functions of the first kind;

$P_{n}$ are the Legendre furctions.

The extraction of the resonance position of the target is done classically, in the case of harmonic source, by spectral analysis, from the modulus of the farfield form function [3]:

$$
\begin{aligned}
\left|F_{\infty}(k r, \theta)\right| & =\frac{2}{k r}\left|\sum_{n=0}^{\infty}(-i)^{n}(2 n+1) A_{n}(k r) P_{n}(\cos \theta)\right| \\
& =\frac{1}{k r}\left|\frac{P_{d i f f}(r)}{P_{\text {inc }}(r)}\right|
\end{aligned}
$$

The integral of the expression (1) on a path $\Gamma$ can $b c$ decomposed into a sum of integrals due to the different branch-points [14]. Each integration around these points corresponds to a surface wave. These waves have their own time and frequency behavior. 


\section{3- Continuous time-scale transform:} Continuous wavelet transform.

\section{3-1: recalls and definitions $[15,16]$}

The continuous wavelet transform of an arbitrary signal $s$ is obtained by the scalar product between this signal and elementary functions, called wavelets. These functions are translated $[\mathrm{b}]$ and dilated copies [a] of a basic function $g$ (named analyzing wavelet) in the time and scale half-plane $(b, a)$. The wavelet transform is given by :

$$
\begin{aligned}
& s(b, a)=\left\langle g_{b, a} \mid s\right\rangle=\int \bar{g}_{b, a} s(t) d t=a \alpha \int g\left(\frac{t-b}{a}\right) s(t) d t \\
& \mathrm{~b} \in \mathrm{R}, \mathrm{a}>0
\end{aligned}
$$

$\ddot{g}$ denotes the complex conjugate of $\mathrm{g} ; \alpha$ depends of the choice of the normalization ( $\alpha=2$. with the nomalization $\left.\mathrm{L}_{2}\right)$.

The transform is inversible if we can define a constant $\mathrm{c} g$ depending only on the wavelet:

$c_{g}=2 \pi \int \frac{|\hat{g}(\omega)|^{2}}{\omega} d \omega<\infty, \hat{g}$ represents the Fourier transform of $\mathrm{g}$.

This necessary condition on the wavelet is called the admissibility one. In practice, it means that $\mathrm{g}$ is of finite energy, $g$ is of zero mean.

The inversion formula is:

$$
s(t)=\frac{1}{c_{g}} \int S(b, a) g b, a(t) \frac{d b d a}{a^{2} \dot{\alpha} \alpha},
$$

$\frac{\mathrm{db} d a}{\mathrm{a}^{2}}$ is the inyariant measure under translation and dilation in the half-plane.

The frequency localization of $g \mathrm{~b}, \mathrm{a}(\mathrm{t})$ depends linearly of $a$, so the decomposition induced will be performed at $\frac{\Delta \omega}{\omega}=$ Constant.

\section{3-2: Extraction of ampliade and frequency modulation laws [17-19].}

We present here, a method essentially based on the stationary phase approximation. The particularity of this method lives in the asymptotic conditions of the signal with respect to the analyzing wavelet, coming from the local properties of the wavelet. way:

One may define the asymptotism in the following

Let $s(t)=A_{S}(t) \cos \left(\Phi_{S}(t)\right)$ an asymptotic signal, then the analytic associated signal is: $\mathrm{s}_{\mathrm{a}}(\mathrm{t})=\mathrm{A}_{\mathrm{S}}(\mathrm{t}) \exp \left(\mathrm{i} \Phi_{\mathrm{S}}(\mathrm{t})\right)$.
Let:

In this part, we will focus on this class of signals.

$$
s(t)=A_{S}(t) \exp \left(i \Phi_{S}(t)\right) \quad ; \quad g(t)=A_{g}(t) \exp \left(i \omega_{0} t\right)
$$

Then:

(2) $\quad S(b, a)=\frac{1}{a^{a}} \int A_{S}(t) A_{g}\left(\frac{t-b}{a}\right) \exp \left(i\left(\Phi_{S}(t)-\omega_{0}\left(\frac{t-b}{a}\right) d t\right.\right.$

The stationary phase criteria at a point $\tau$ (a) leading to an approximation of the integral (2) is:

$$
\frac{d \Phi_{S}(t)}{d}=\frac{\omega_{0}}{a} \text { en } t=\tau(a)
$$

If we suppose the signal to be asymptotic with respect to the wavelet at $\tau(a)$, ie: $A_{S}(t)$ varies slowly in front of Ag $\left(\frac{t-b}{a}\right)$, we have:

(3)

$$
S(b, a)=\frac{1}{a^{d}} A_{S}(\tau(a)) \int A_{g}\left(\frac{t-b}{a}\right) \exp \left[i\left(\Phi_{S}(t)-\omega_{0}\left(\frac{t-b}{a}\right)\right] d t+\varepsilon_{1}\right.
$$

With a second order limited expansion of the phase of the integral (3) at the same point $\tau(a)$, we obtaine:

$$
\begin{aligned}
S(b, a) & =\frac{1}{a^{d}} A_{S}(\tau(a)) \exp \left[i\left(\Phi_{S}(\tau(a))-\omega_{0}\left(\frac{\tau(a)-b}{a}\right)\right] x\right. \\
& x \int A_{g}\left(\frac{t-b}{a}\right) \exp \left[i\left(\frac{1}{2}(t-\tau(a))^{2} \frac{d^{2} \Phi_{S}(\tau(a))}{d t^{2}}\right)\right] d t+\varepsilon_{1}+\varepsilon_{2}
\end{aligned}
$$

Suppose $A g(t)=\exp \left(-\frac{1}{2} t^{2}\right.$ ) (case of the Morlet wavelet), then $S(b, a)$ is a gaussian integral. We note:

$$
\Phi_{S^{\prime \prime}}^{\prime \prime} \frac{d^{2} \Phi_{S}(\tau(a))}{d t^{2}}, \quad S(b, a)=M(b, a) \exp \left(i \Phi_{T}(b, a)\right)
$$

Then:

$$
\begin{gathered}
\Phi_{T}(b, a)=\Phi_{S}(\tau(a))-\omega_{0}\left(\frac{\tau(a)-b}{a}\right)+\frac{1}{2} \operatorname{Arctan}\left(a^{2} \Phi_{s}^{\prime \prime}\right)+ \\
+\frac{1}{2}(b-\tau(a))^{2} \frac{\Phi_{s}^{\prime \prime}}{1+a^{4} \Phi_{s}^{\prime \prime}}
\end{gathered}
$$

$\left.M(b, a)=\frac{\sqrt{2 \pi} A_{s}(\tau(a))}{a^{2}\left(1+a^{4} \Phi^{n} s^{2}\right)^{1 / 4}}\right) \exp \left(\frac{1 a^{4} \Phi^{\prime \prime} s^{2}}{2\left(1+a^{4} \phi^{\prime \prime} s^{2}\right.}\left(\frac{b-\tau(a)}{a}\right)^{2}\right)$

and

$$
\begin{aligned}
& \frac{\partial \Phi_{T}(b, a)}{\partial b}=\frac{\omega_{l}}{a} \text { at } b=\tau(a) \\
& M(b, a) \text { is maximum }
\end{aligned}
$$

$S(\tau(a), a)=C^{s t} s(t)$ 


\section{a-Interoretation}

We will call 'ridge' the curve $b=\tau(a)$ and the restriction of the wavelet transform along the ridge will be call 'skeleton'.

The ridge detection consists on the search of the points over the half-plane $(b, a)$ such as: $\frac{\partial \Phi_{T}(b, a)}{\partial b}=\frac{\omega_{0}}{a}$. This set of points defines a curve where the modulus is maximum.

The ridge and the skeleton have the following properties:

$-S(\tau(a), a)$ is equal to $s(t)$ up to one known coefficient.

-The ridge gives an estimation of the frequency modulation law.

-The modulus of the skeleton gives an estimation of the amplitude modulation law.

\section{b-Errorestimation.}

The error majoration is:

$$
\begin{aligned}
& \varepsilon_{1}<K_{1} \cdot a \cdot\left\|A_{S}^{\prime}(\tau(a))\right\|_{\infty} \\
& \varepsilon_{2}<K_{2} \cdot a^{3} \cdot\left|A_{S}(\tau(a))\right| \cdot\left\|\Phi_{S}{ }^{(3)}(\tau(a))\right\|_{\infty}
\end{aligned}
$$

Remark: One of the conditions required for this approximation is the asymptotism of the signal with respect to the wavelet. In practice, this condition is controlled since we can choose the wavelet. A few asymptotic signal will require a wavelet well localised in time. This method compared to the one used in [11] can be applied to wave packets containing few oscillations. This method can be applied to impulse signals scattered by elastic targets of simple geometric shape.

\section{Time-scale analysis of echoes scattered by a spherical elastic shell.}

We consider spherical scatterers immersed in water. The thickness of the shells is small with ratio of radii $r_{j} / x_{c}$ of 0.9 (Fig. 1,3), 0.67 (Fig.2) and 0.96 (Fig. 4), ( $r_{i}, r_{\mathrm{e}}$ : internal, external radius $r_{e}=3 \mathrm{~cm}$ ). They are made in duralumin (ie: alloying of $95 \%$ aluminium and $3,5 \%$ copper), except for the last one which is made in nickelmolybdene. The transducers used for experiments have either a central frequency of $500 \mathrm{kHz}$ with a band-width at $3 \mathrm{~dB}$ of $400 \mathrm{kHz}$ (Fig. 1,2) or a central frequency of $250 \mathrm{kHz}$ (Fig 3,4) with a band-width of $150 \mathrm{kHz}$.

We have applied a wavelet analyzis both on experimental and simulated signals, but we present here experimental results. For each analyzis we dispose of two complementary informations on the wavelet transform: the phase (b) and the modulus (c). The impulse response of shells is displayed in (a).

The modulus of the transform is shown in linear scale with a density of points. The modulus is maximum (minimum) when it is black (white). The phase representation is between $(0,2 \pi)$. The ridge is represented by black dots over the phase diagram. The abscissa represents the transiation parameter (time). The ordinate represents the dilation parameter in hyperbolic scale (linear in frequency), decomposed in 150 voices. The analyzing wavelet (standard Morlet wavelet) has been defined with the following caracteristics: $\omega_{0}=5.336$, and $g(t)=0$, for $a=1$, when $\lg (t)<10^{-5}$.

The sampling rate of the time signal is respectively $10^{7} \mathrm{~Hz}, 1.810^{6} \mathrm{~Hz}, 10^{7} \mathrm{~Hz}, 10^{7} \mathrm{~Hz}$. The analysis is performed with a frequency range of $[833.33 \mathrm{kkJZ}$ to $208.33 \mathrm{kHz}],[900 \mathrm{kHz}$ to 56,25$][625 \mathrm{kHz}$ to $156 \mathrm{kHz}]$ and [500kHz to $78 \mathrm{kHz}]$

Roughly speaking, the dispersion of the shell increases the inclination and the attenuation of waves packets during time. The dispersion law of the phase velocity can be obtained either from the modulus or from the phase of the wavelet transform:

- by extraction of the maxima of energy of the waves packets (whispering echoes) for each scale (analysis of the modulus);

- by extraction of the ridge (fig. 1-4.b) (analysis of the phase).

The analysis of two successive waves packets of the same type allows us to define the dispersion law of the group velocity. The problem is sometimes the measure error generated by the ambient noise during the experiment. In this case, even the wavelet transform has shown a good efficacy [17-19], it is necessary to combine filtering methods with the wavelet transform.

We can see on the figures $c$ in accordance with the theoretical study of the scattering, the specular echo or geometric contribution (Fig: 2,4$)\left(1^{\text {st }}\right.$ waves packet) and the surface contribution (Fig: 1- 4). This contribution for the shell of ratio of radii 09 (fig.1.c) is the whispering wave after one travel around the target ( $1^{\text {st }}$ waves packet) and after a $2^{\text {nd }}$ travel ( $3^{\text {th }}$ waves packet). The $2^{\text {nd }}$ waves packet is not dispersive. For each echo, the ridge gives an estimation of the dispersion law of the phase velocity (fig 1.b). The horizontal ridges are characteristics of the nondispersive echo.

The figure 2 represents the wavelet transform of a signal scattered by a duralumin shell of $r_{i} / r_{e}=0.67$. The echos structure is similar to the figure 1 . The modulation law is representative of the thickness of the shell. The frequexcy of the ridge is over $366 \mathrm{kHz}$ to $669 \mathrm{kHz}$.

The figure 3 displays the analysis of the response of the same shell than figure 1 , but with a different transducer. The modulation law varies with respect to the frequency of the excitation. The frequency of the ridge is here, over $275 \mathrm{kHz}$ to $500 \mathrm{kHz}$.

The figure 4 represents the wavelet transform of a signal backscattered by a nickel-molybdene shell of $r_{\gamma} / r_{e}=0.96$. Again, the echos structure is similar to. fig 1 . The analysis of this figure shows the relation between the modulation law and the shell chemical composition. Ringe frequency is $223 \mathrm{kHz}$ to $398 \mathrm{kHz}$. 


\section{5- Conclusion}

The dispersive behavior of the surface waves has led us to choose a time and scale method. By an another way the separation of close echoes requires a linear method.

The ridge associated to the continuous wavelet transform seems to be a promising tool for the systematic study of this type of waves. We may considered the response of the target as an acoustic signature with respect to the analyzing wavelet.

\section{Acknowledgements}

We thank gratefully Dr Sessarego J. P., Dr Poirée B. and Sageloli $Y$., for the experiments performance in the laboratory in Marseille (L.M.A) and for their helpful advices.

This study has been performed in the framework of the G.D.R. ondelettes of the Centre National de la Recherche Scientifique

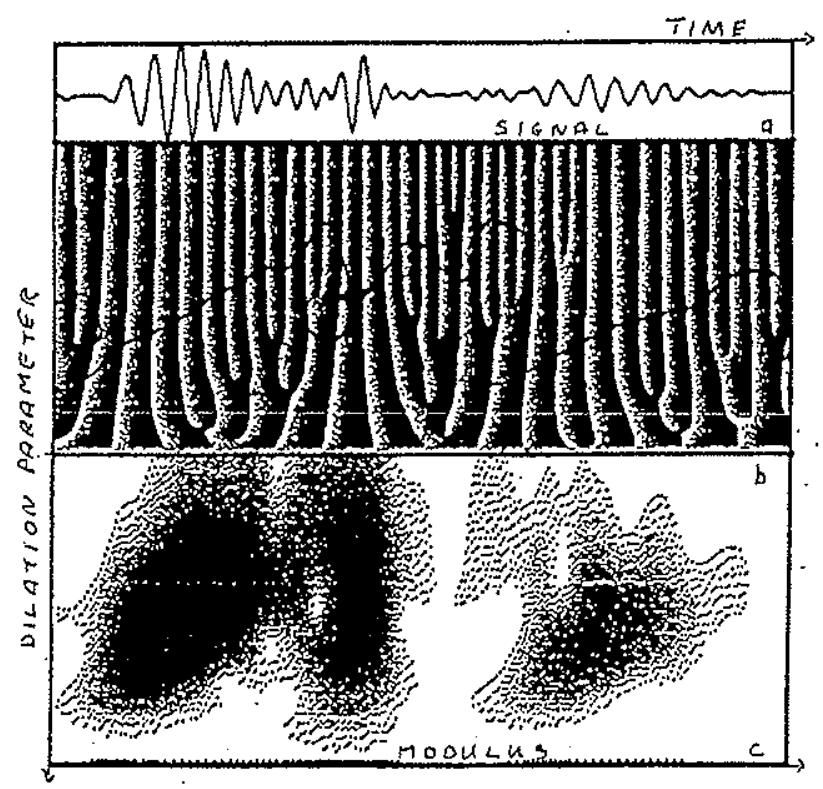

Fig. 1: Impulse response of a thin spherical shell of duralumin with an external radius $r_{e}=0.03 \mathrm{~m} . r_{l} / r_{e}=0.9$

( $r_{i}$ is the internal radius). (whispering waves: 1 and 2 ). Central frequency $=500 \mathrm{kHz}$

Ridge frequency is $366 \mathrm{kHz}$ to $669 \mathrm{kHz}$

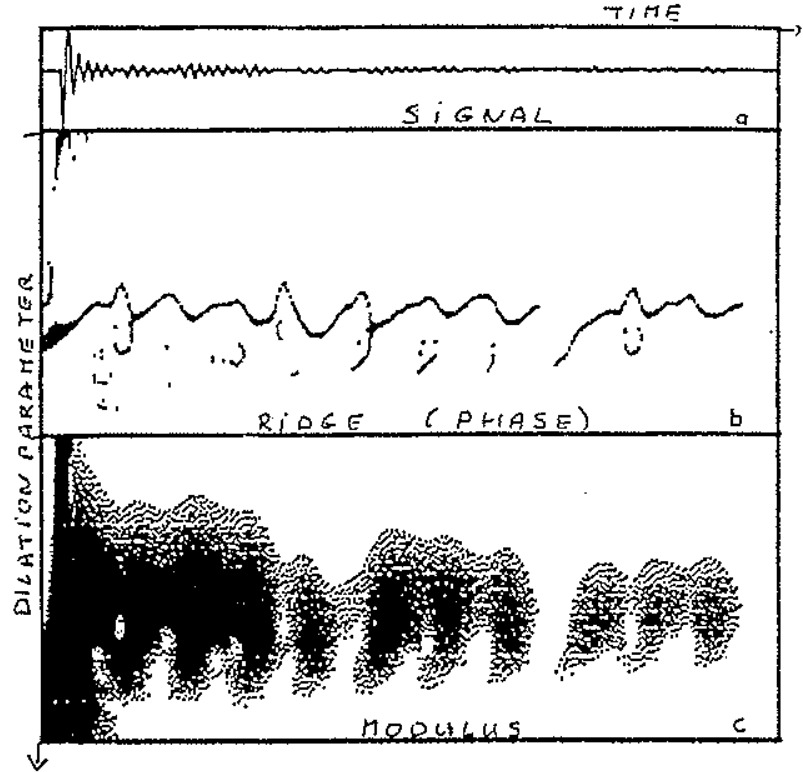

Fig. 2: Impulse response of a thin spherical shell of duralumin with an external radius $r_{e}=0.03 \mathrm{~m} . \mathrm{ri}_{i} / r_{e}=0.67$

( $r i$ is the internal radius). Central frequency $=500 \mathrm{kHz}$ Ridge frequency is $275 \mathrm{kHz}$ to $500 \mathrm{kHz}$

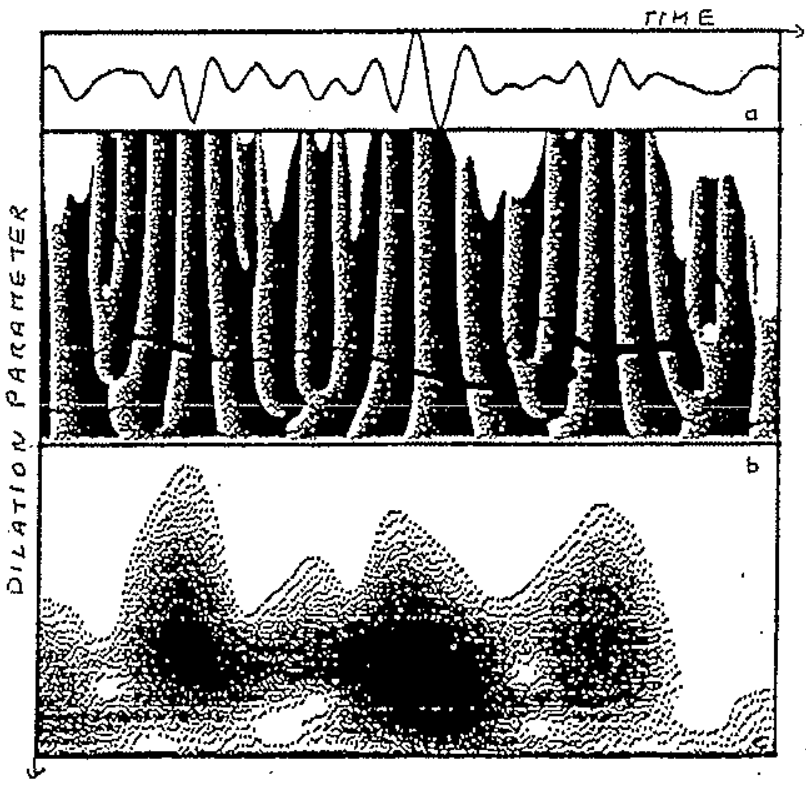

Fig. 3: Impulse response of a thin spherical shell of duralumin with an external radius $r_{e}=0.03 \mathrm{~m} . r_{i} / r_{e}=0.9$

$\left(r_{i}\right.$ is the internal radius). Central frequency $=250 \mathrm{kHz}$ Ridge frequency is $223 \mathrm{kHz}$ to $398 \mathrm{kHz}$ 


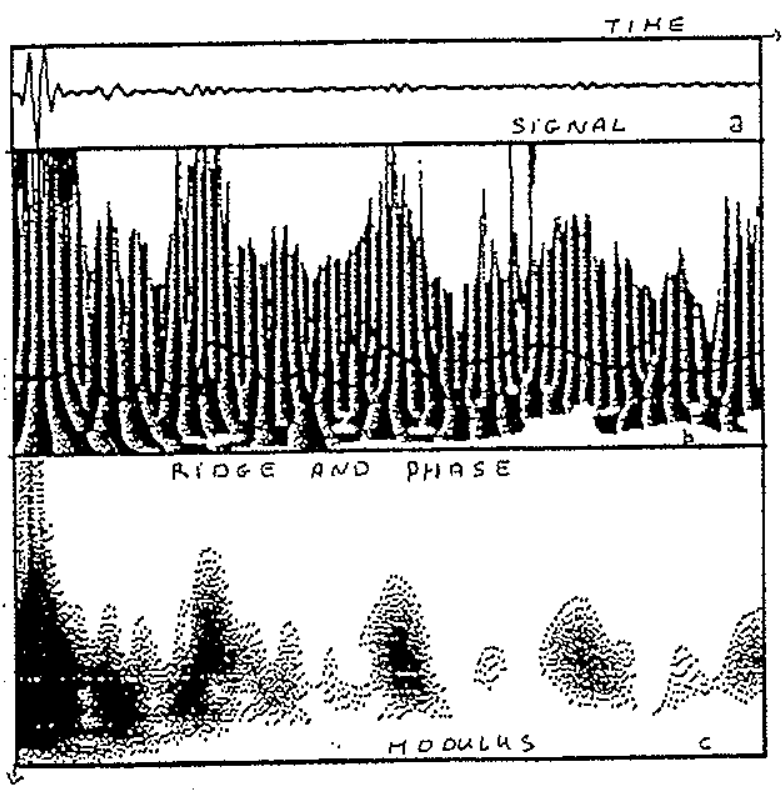

Fig. 4: Impulse response of a thin spherical shell of nickel-molybdene with an external radius $r_{e}=0.03 \mathrm{~m}$. $r_{i} / r_{e}=096$

( $r_{i}$ is the internal radius). Central frequency $=250 \mathrm{kHz}$ Ridge frequency is $136 \mathrm{kHz}$ to $401 \mathrm{kHz}$

\section{Referenctes}

[1] L. Flax, L. R. Dragonette, H. Uberall, 1978, "Theory of elastic resonance excitation by sound scattering", J. Acoust. Soc. Am., 63 (3), 723-731.

[2] A. Derem, 1980, "Diffusion acoustique par des corps cylindriques immergés: aspects géneraux, Rev. Cethedec $72.47-60$.

[3] N. Gespa, "La diffusion acoustique par des cibles Élastiques de forme geométrique simple. Theorie et expériences", CEDOCAR Ed, (1987), Paris

[4] N.C. Yen, 1987, Time and frequency representation of acoustic signals by means of the Wigner distribution function: implementation and interpretation, J;Acoust; Soc. Am. 81 (6), 1841-1850.

[5] D. Brill, G. Gaunaurd, 1987, "Resonance theory of elastic waves ultrasonically scattered from an elastic sphere", J. Acoust. Soc. Am., 81, 1-21.

[6] M. Talmant, G. Quentin, J.I. Rousselot, Subrahmanyam J.V., H. Uberhall, 1988, "Acoustic resonances of thin cylindrical shells and the resonance scattering theory", J. Acoust. Soc. Am., 84(2), 681-688.

[7] J. L. Rousselot, A. Gérard, J.P. Sessarego, J. Sageloli, 1988, "Réponse basse fréquence d'une coque sphérique mince immergée" , Acustica, 66, 203-213.

[8] "Electromagnetic and Acoustic Scattering. Detection and Inverse Problems: 31 mai-3 Juin 1988". World Scientific, (1989), Singapore.

[9]Quentin G., Derem A. and poiree B., 1989, Group velocity and acoustical resonances J. Phys. 50, 1943-1952 [10] J.P. Sessarego, J. Sageloii, P. Flandrin, M Zalcharia 1989. "Time-frequency analysis of signal related to scattering problems in acoustics. Part I:Wigner-Ville analysis of echoes scattered by a spherical shell", (Wavelet, time-frequency methods and phase space, Springer-Verlag, Berlin, 147-153.

[11]: G. Saracco, C Gazanhes, J. Sageloli, J.P. Sessarego, J.P., 1989, "Analyse temps-échelle de la diffusion acoustique par des coques spheriques en régime impulsionnel", Journ. Acoust., 1990, vol 34p. 381-301 [12] H. Utberall, LR. Dragonette, L. Flax, 1977, "Relation between creeping waves and normal modes of vibration of a curved body", J. Acoust. Soc. Am., 61 (3), 711-715.

[13] A. Derem, 1987, "Théorie de la matrice $S$ et transformation de Sommerfeld-Watson", (Ch.9, N. Gespa, La diffusion acoustique par des cibles elastiques de forme gémétrique simple), CEDOCAR edit, Paris, 189-280.

[14] Saracco G., 1989, "Propagation acoustique en régime harmonique et transitoire à travers un milieu inhomogène: Méthode asymptotique et transformation en ondelettes", These, U.E.R. II, Marseille-Luminy.

[15] A. Grossmann, J. Morlet, 1984, "decomposition of Hardy functions into square integrable wavelets of constant shape", Soc. Int. Am. Math., Journ. of Math. Analys., vol no $15,723-736$.

[16] Proceed "Wavelet, Time-frequency methods and Phase Space", Marseille-Luminy, dé 1987, J.M. Combes, A. Grossmann, P. Tchamitchian Eds, Springer-Verlag, (1989), Berlin.

[17]: B. Escudie, A. Grossmann, R. Kronland-Martinet, B. Torresani, 1989, "Analyse par ondelettes de signaux asymptotiques, Emploi de la phase stationnaire", 12eme Colloq. G.R.E.T.S.I. (Juan-les-pins)

[18] P. Guillemain, "Analyse et modelisation de signaux acoustiques. Application de la transformée en ondelettes." Report of D.E.A. Marseille 1990

[19] P. Guillemain, R. Kronland-Martinet, B. Martens, "Estimation of spectral lines with the help of the wavelet transform. Application in N.M.R. spectroscopy", to appear in proceed. "wavelet and application", Marseille 1990. 